\title{
Motor mechanism in Separation Test of Coal Mine Isolation Switch and Controllability Test System
}

\author{
Hongkui ZHANG \\ CCTEG Shenyang Research Institute, Fushun 1131226, China
}

Fucheng LANG

Electric Power Research Institute of State Grid Liaoning Electric Power Co., Ltd., Shenyang 110006, China.

High Voltage and Large Current Laboratory of State Grid Corporation, Shenyang 110006, China

Hao WANG

Technical Center for China Tobacco Yunan Industrial Co. Ltd, Kunming 650231, China

\begin{abstract}
In order to improve the reliability of mining electrical equipment and realize intelligence of the separation test of the coal mine isolation switch operation process, the motor mechanism is put forward. We designed controllable testing system based on coal mine isolation switch breaking test the existing operating mechanism including three-phase bridge driver circuit, position and stroke detection circuit, and testing in the way of different duty than the single test. The test results show that the slope (velocity) of the curve is changed with the duty cycle, which proves the controllability of the running process of the motor mechanism. KEYWORD: Coal mine; Isolation Switch; Motor Mechanism; Controllability
\end{abstract}

\section{INTRODUCTION}

In China, the energy structure continuous optimization, hydropower, wind, solar and biomass and other non-fossil energy gradually entered the industrialization development mode. However, the energy resources characteristics of rich in coal, poor in oil and gas decided coal still is the main energy in our country. According to the energy development strategy action plan (2014-2020) requirements, by 2020, China's total energy consumption will be controlled at about 480 million tons of standard coal, coal total consumption 420 million tons.

Due to the bad working environment of coal mine, requirements about the reliability and stability of electrical equipment is higher. According to GB/T5590-2008 Mining explosion-proof low voltage electromagnetic starter and MT111-2011 Mining explosion-proof low voltage alternating vacuum electromagnetic starter, the isolation switch must have the ability of breaking current, and the test condition is positive and reverse each operation 3 times. The traditional coal mine isolation switch has backward technical level, poor reliability, and low controllability. Therefore, it is the development trend of coal mine electrical equipment inspection field to study the new operating mechanism to meet the requirement of the separation of the coal mine

\section{COAL MINE ISOLATION SWITCH}

Coal mine isolation switch is the important components of flameproof type vacuum electromagnetic starter, mining flameproof type coal electric drill transformer integrated protection device, mine flame proof type multi loop combination switch and mine flame proof and intrinsically safe type soft starter and other electrical equipment. Playing the function of to breaking fault current (if contactor failure, no breaking current), electrical isolation and no load commutation in coal mine power grid. Figure 1 shows the physical map of mine isolation switch. GHK - 400/1140 isolating switch of coal mine main technical parameters as shown in table 1 .

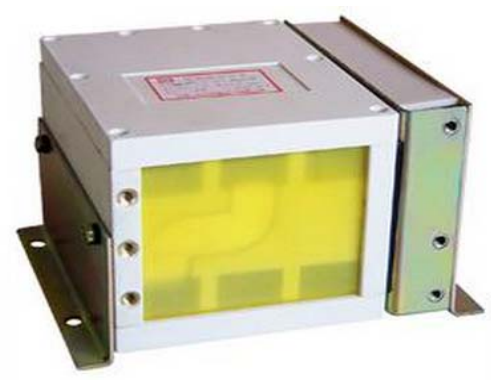

Fig. 1 Physical map of mine isolation switch

The coal mine isolation switch composed of contact system and operating mechanism, and contact system consists of three-phase static contact, forward moving contact group and the reverse dynamic contact group, closed across the arc gate arc shield and insulation resistance of the arc plastic frame and the shell. The contact system is made of single break type structure, whose feature is the static contact is made of double L type back type symmetrical structure. The operating mechanism is made of operating 
panel, coaxial four connecting rod mechanism, manipulator and storage components spring linkage. The two output shafts of the positive and negative moving contact groups are connected with the respective operating arms. The power source is input through the static contact. When the operating panel is zero, the positive and negative moving contact group is in a disconnected state, so the power source is isolated.

Tab 1 GHK - 400/1140 isolating switch of coal mine main technical parameters

\begin{tabular}{cc}
\hline project & parameter \\
\hline rated voltage $(\mathrm{V})$ & 1140 \\
rated current $(\mathrm{A})$ & 400 \\
breaking capacity(A) & $\geq 400$ \\
operating Angle $\left({ }^{\circ}\right)$ & \pm 72 \\
maximal operating force $(\mathrm{N})$ & 35 \\
mechanical life & 6000 \\
power frequency withstand voltage $(\mathrm{V})$ & 4200 \\
rated frequency $(\mathrm{Hz})$ & 50 \\
\hline
\end{tabular}

When the operating panel clockwise rotation, it will drive a group of four bar linkages and then driven positive moving contact group to rotate and a static contact are closed, the power is switched on. After four bar linkage over dead it will self-locking, positive moving contact won the final pressure and the spring is tensile to energy storage; The oth er group off our bar linkages makes the negative moving contact group far away from the static contact, and forms the positive and negative moving contact group mutual lock state. If breaking, operate panel will counterclockwise to zero. When the annular groove driven four-bar linkage dead spring immediately release can drive forward dynamic contact group rapid separation, cut off the power supply; When the panel rotates from zero counterclockwise, negative moving contact and static contact closed connected, and positive moving contact group away from the static contact. When reverse connect cross conductive plate, it will change the phase sequence of the output power, realizing commutation.

\section{BREAKING TEST OPERATING MECHANISM}

\subsection{Traditional Operating Mechanism}

The traditional operating mechanism is divided into the artificial breaking mechanism and the pneumatic breaking mechanism. Artificial breaking depend on the operating handle communicate with isolating switch shaft and experiment needs two people, they need pulling the rope quickly after test current access about $100 \mathrm{~ms}$ to driven isolating switch shaft in order to complete the isolation switch breaking experiment. This mode of operation is too dependent on the experience of test person and poor in stability, as well as potential safety hazards. The operating handle is shown in Figure 2.

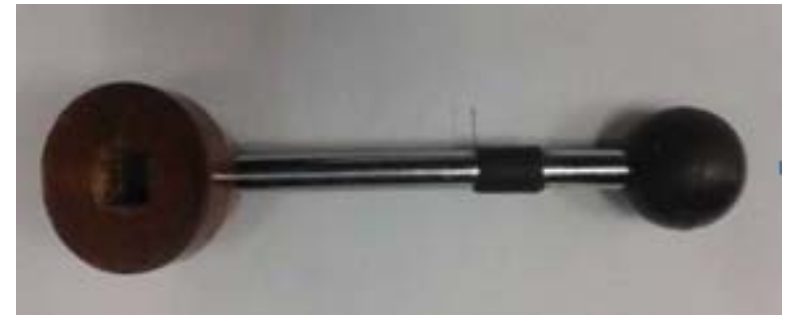

Fig. 2 Physical map of operating handle

The pneumatic actuating mechanism controls the rotation of the swing cylinder, drives the isolation switch rotating shaft to drive the isolation switch to complete the split test. This operation method uses the mechanical device to replace the manual operation, which guarantees the operating force of the breaking process and realizes the automatic operation. However, the test device has complex structure, large accumulated movement tolerance, low stability and poor controllability, and can not achieve the precise adjustment of the breaking speed and time. The pneumatic actuator is shown in Figure 3.

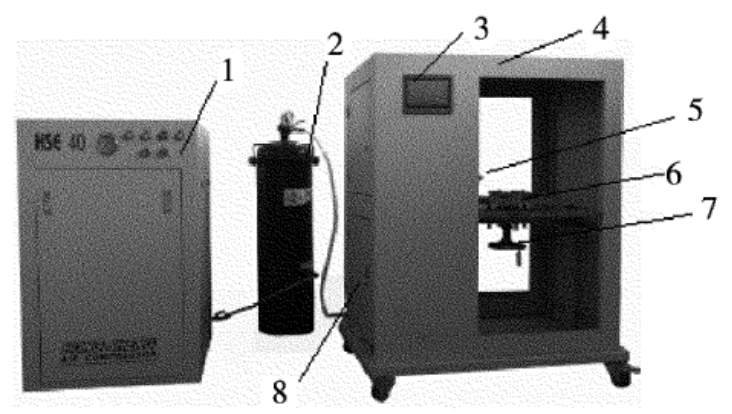

1 is the air compressor, 2 is the gas tank, 3 is the touch screen and control, 4 is the operating platform, 5 is the rotating shaft, 6 is the installation frame, 7 is the lifting mechanism, 8 is the solenoid valve group

Fig. 3 Physical map of pneumatic actuator

\subsection{Motor Mechanism}

Motor mechanism is a comprehensive application of electrical machine, power electronic technology and modern control theory in the field of separation test technology of coal mine isolation switch. The mechanism takes the brushless DC motor as the core, using the electric motor to drive the rotating shaft of the coal mine isolation switch, and then drives the moving contact and the static contact to separate. The breaking test operation is completed. The motor mechanism is mainly composed of an motor body which can generate controllable electromagnetic torque, a photoelectric encoder and a control system.

In order to facilitate the quantitative analysis of the controllability of the motor mechanism, the magnetic saturation effect, cogging effect, permanent magnet role in blocking, armature reaction, magnetic and eddy current loss is neglected, and mo- 
tor mechanism is the ideal state (Three phase winding is completely symmetrical, and the inner surface of the stator is smooth and uniform). The threephase winding voltage balance equation can be expressed as:

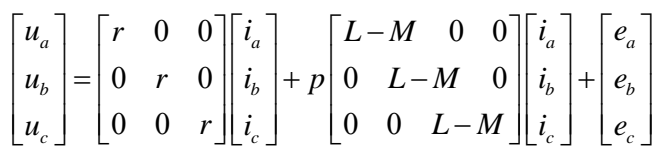

The motor body was composed of permanent magnets, winding, rotor, stator and rotor. Powered coal mine isolation switch motion is generated by the motor body, control system for collecting optical encoder feedback motor rotor position signals and send the control instruction to achieve reasonable motor reversing, and according to the coal mine isolation switch breaking test requirements of motor for precise control. The motor body structure is shown in figure 4.

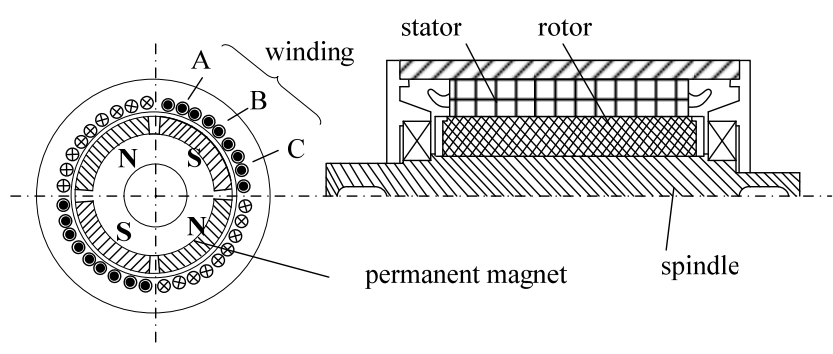

Fig. 4 Structure diagram of motor body

\section{CONTROLLABILITY TEST SYSTEM}

\subsection{Designing Hardware}

Coal mine isolation switch motor mechanism test system using the powerful data processing capability of digital signal processor (DSP). The TMS320F2812 DSP-type is used as the core processing chip in the monitoring system. As for the TMS320F2812, adapting the Harvard bus structure, working in the highest $150 \mathrm{MHz}, 16$ pathway 12-bit ADC modules (the fastest conversion time is $80 \mathrm{~ns}$ ). And the smallest system of DSP is built by the power supply module, the clock module and the online programming interface.It can capture the external input instruction, and according to the position of motor mechanism transmitting control signal to drive the motor to move. Meanwhile changing control signal cycle and getting motor travel characteristic curve, and then testing controllability. The testing system mainly includes the control panel, power module, DSP, three phase bridge inverter circuit, rectifier circuit, stroke detection unit, motor mechanism and and coal mine isolation switch. Its structure is shown in figure 5.

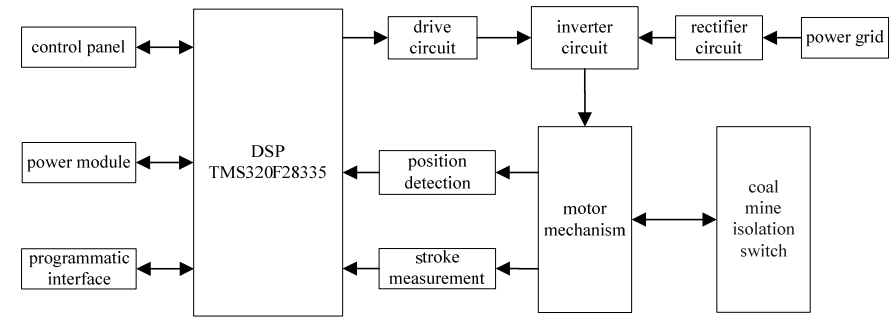

Fig. 5 Structure diagram of controllability test system for motor mechanism

\subsection{Designing Software}

Coal mine isolating switch motor test system hardware is the foundation of realizing function of each part, and the realization of various functions of system and information feedback is achieved through software. Test system in this paper, a modular thought as the instruction of the control system software program design and debugging. According to the design of hardware circuit and the corresponding software system development of the main program flow chart, as shown in figure 6.

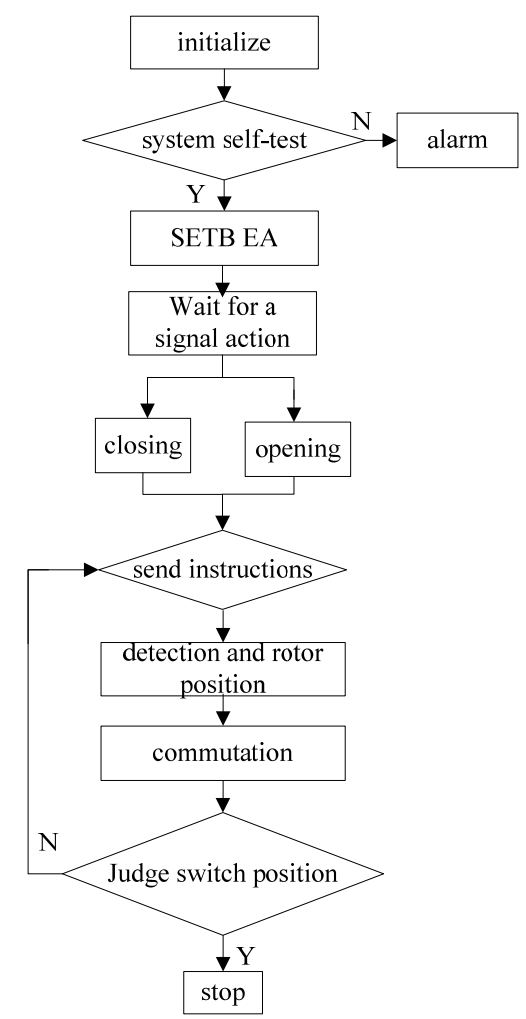

Fig.6 Main program flow diagram of test system

\subsection{Controllability Test}

In order to verify the controllability of the motor mechanism of the coal mine isolation switch, the test is different duty cycle single. Different duty cycle single test process is divided into three stages of 150 ms, among which $\mathrm{A} \sim \mathrm{B}$ duty cycle is $75 \%, \mathrm{~B} \sim \mathrm{C}$ is $60 \%, \mathrm{C} \sim \mathrm{D}$ is $90 \%$, and the test results are shown in Figure 7. It can be concluded that the speed of motor varies with the change of the duty cycle of the driv- 
ing signal. The speed regulation effect is obvious. Hence, proving that the operation speed of the motor mechanism is controllable.

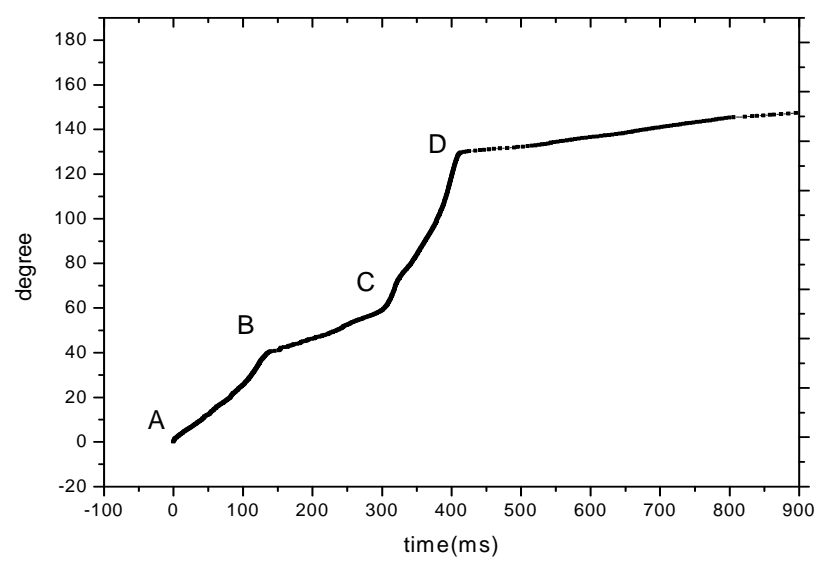

Fig. 7 Motor no-load speed control curve

\section{CONCLUSION}

The energy resources characteristics decided coal is the main energy in our country. According to GB/T5590-2008 Mining explosion-proof low voltage electromagnetic starter and MT111-2011 Mining explosion-proof low voltage alternating vacuum electromagnetic starter, the isolation switch must have the ability of breaking current. Breaking test is an important index to measure the performance of coal mine isolated switch and related products. For the coal mine isolation switch breaking test existing operating mechanism, we designed controllability test system based on the theory of mine coal isolation switch structure, working principle and the controllability of the motor mechanism. The experimental results show that the motor mechanism movement process is completely controllable, and it lays the foundation for the development of the breaking test technology of the coal mine isolation switch.

\section{ACKNOWLEDGMENT}

This paper belongs to the project of youth fund of China Coal Technology \& Engineering Group Corp (No. (2014QN015); (2013MS014)). Finished content in this article is researched due to the common effort of the whole team, thank you for your support and help, thanks my colleagues. In the process of finish this article also get help from many friends, thanks. This article have many shortcomings that also hope that experts and scholars do comment.

\section{REFERENCES}

Ai-min Liu, Xin Lin. Optimization design to linear induction motor used in circuit breaker operating mechanism [J]. Electric Machines and control, vol.4,pp. 528- 532,2009.

Atallah K, Ziqing Zhu. Armature reaction field and winding I nductances of slotless permanent-magnet brushless machines .IEEE Trans on Magnetics, vol. 5,pp.37373744.2000.

Bosma A, Cameroni R. Introducing a new generation of operating mechanism for high voltage ac circuit breaker[J]. Journal of Electrical \& Electronic Engineering, 2012, 21(3):233240.

Balanathan Ragu, Pahalawaththa Nalin C, Annakkage Udaya D. Modeling Induction Motor Loads for Voltage Stability Analysis.Int J Electr Power Energy Syst, vol. 8, pp.469,2002.

Cathey, J. MATLAB Analyse of Motor Principle and Design. Beijing: China Electronic Press, 2006. pp.7.

Ho Kwon, S.-Y.Ju Lee. A study on the permanent magnet overhang effect in permanent magnetic actuator using 3dimension equivalent magnetic circuit net work method, The Sixth International Conference on Electrical Machines and Systems, ICEMS. Beijing. pp.222-225,2003.

Saitoh H, Iehikawa H, Nishijima A, et al. Research and development on $145 \mathrm{kV} / 40 \mathrm{kA}$ one break vacuum circuit breaker[C]. Proceedings of the IEEE Power Engineering Society Transmission and Distribution Conference, Yokahama, Japan, 2012, 7(2):1465-1468.

Xin Lin, Deshun Wang, Jianyuan Xu, Yueqian Ma. Application of Single Neuron PID Controller in Movement Control of High Voltage Circuit Breaker.Transactions of China Electrotechnical Society, vol.1,pp. 1-7,2009.

Xin Lin, Hong-kui Zhang, Yong-xiang Li, Jian-yuan Xu. Research on Mechanical Characteristics Monitoring System for High-voltage Circuit Breaker Motor Operating mechanism,ICEMS'2011, PS-MSG-13.

Yongxiang Li, Xin Lin, Jianyuan Xu. Design of a Novel Permanent Magnet Brushless DC Motor-Driven Operating Mechanism for High-Voltage Circuit Breaker and Its Dynamic Simulation. Power System Technology, vol. 1,pp.185-189,2010. 